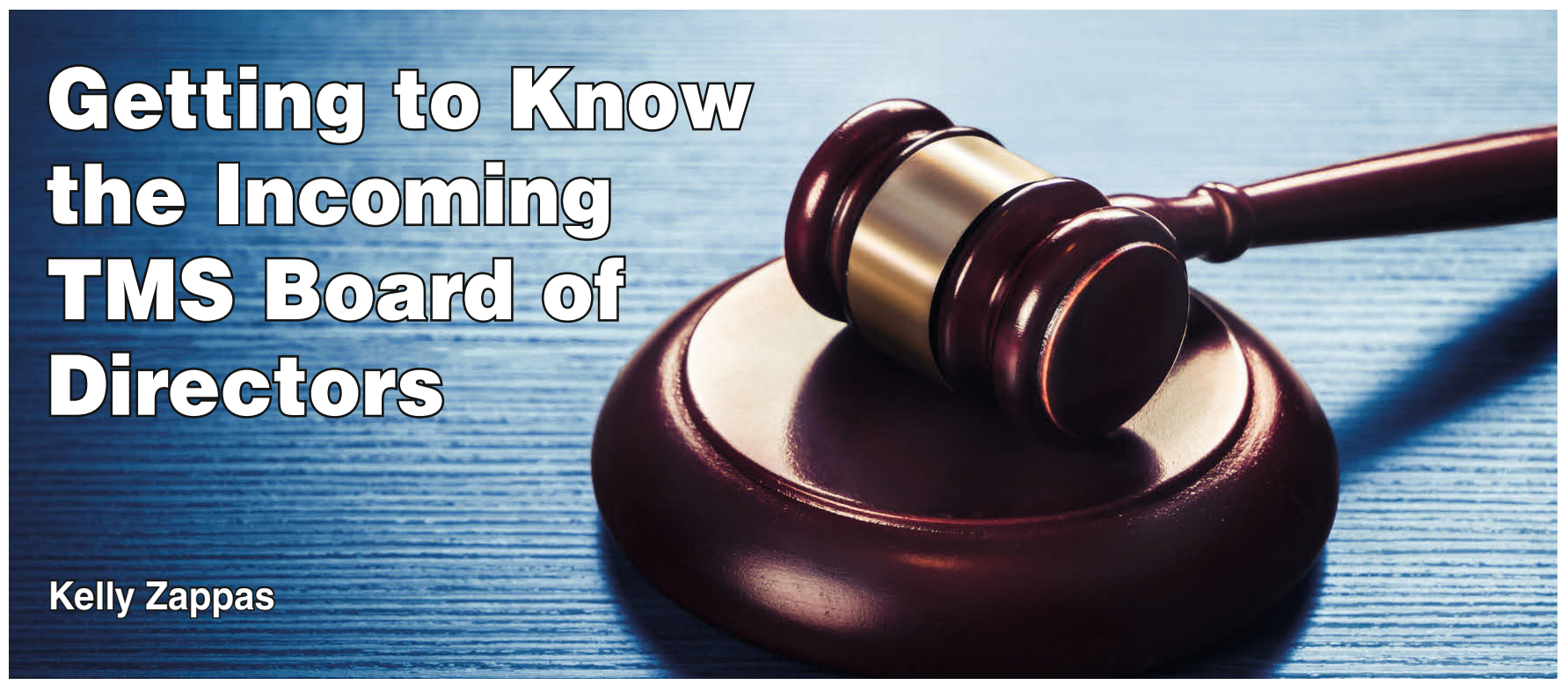

In 2021, TMS will welcome two new members to its Board of Directors. Jud Ready of the Georgia Institute of Technology (Georgia Tech) and Tim Rupert of the University of California, Irvine (UCI) will begin their threeyear terms on the TMS Board of Directors at the end of the
TMS 2021 Annual Meeting \& Exhibition, March 14-18, 2021. Take a few moments today to get to know these active TMS volunteers, to learn how TMS has influenced their careers, and to gain insight into what they hope to accomplish during their time in office.

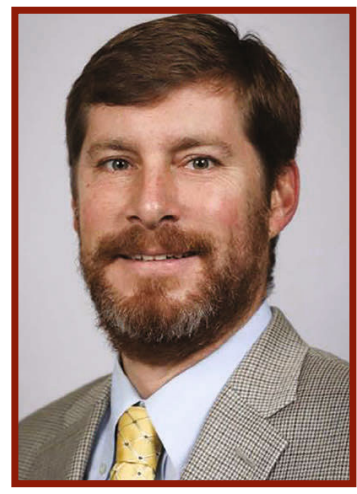

\section{Jud Ready} Vice President

Jud Ready first became involved with TMS in 1992 as a member of the Georgia Tech student chapter and later took on his first major leadership role as chapter president. He presented his work at his first TMS annual meeting in 1994, and he has attended the meeting every year since, missing the conference only when his children were born.

"Even then, my students went," he pointed out. "So, my research has been presented at every TMS Annual Meeting for more than a quarter century."

Ready, who is now deputy director, Innovation Initiatives, at Georgia Tech, says there are two things that keep him coming back to TMS meetings year after year. "It's the people and the science," he said. "TMS is so broad. The ability to keep learning new things keeps me coming back."

The network he's built at TMS — including collaborators, program managers, and friends — has also had a dramatic impact on his career.

"I would be nowhere close to where I am now, professionally, without the connection, the content resources, the professional relationships, and also the true friendships I've developed through my involvement with TMS," he said. "There's a great camaraderie compared to other societies. It's a much more friendly atmosphere."

It's no surprise, then, that one of the things Ready is most looking forward to during his term as president in 2022 is a return to normalcy with face-to-face meetings and live events. Still, he notes the benefits of the virtual events that have been held in the past year.

"Practicing doing conferences virtually has opened a lot of new opportunities for content delivery," he said. "It will be interesting to see how this adds to TMS's wealth of knowledge and to see how we fold these new capabilities into future events."

Overall, Ready hopes to contribute enthusiasm, amicability, and friendliness during his term on the TMS Board of Directors. "That's what sets TMS apart from other Societies. The social interactions that can feel forced or awkward at other conferences come naturally at TMS."

"I would be nowhere close to where I am now, professionally, without the connection, the content resources, the professional relationships, and also the true ffriendships l've developed through my involvement with TMS." -Jud Ready 


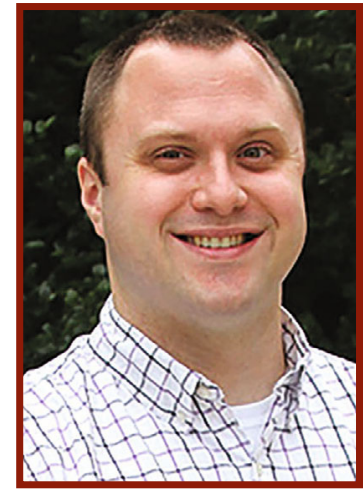

\section{Tim Rupert Programming Director}

Tim Rupert's involvement with the Society began at the TMS 2008 Annual Meeting \& Exhibition, when he was a firstyear graduate student giving his first conference talk.

"I found a community that valued my work and provided an amazing forum for scientific discussion," he said.

"Attending TMS meetings has let me share scientific ideas with colleagues and build new collaborations. Major TMS meetings like the Annual Meeting and the MS\&T meeting are still 'must attends' for me today."

Rupert, who is now associate professor of materials science and engineering at UCI, found that involvement in the Society also offered a number of less obvious professional benefits.
"I found many career growth opportunities associated with the bottom-up organization structure of TMS, with the chance to organize symposia and become involved in committee leadership being specific examples," he said.

As the incoming Programming Director, Rupert recognizes the importance of the Society's programming decisions during this unusual time.

"Programming is always an area that is dynamic and high-impact, as the hot areas of materials science evolve quickly," he said. "But this space is especially important now as we all deal with COVID and its impact on our way of interacting with our peers."

"I am excited to dive into this position at a time when we truly need innovation in how we operate," he continued. "There will certainly be challenges and perhaps even occasional missteps, but it will also be exciting to have a chance to revamp certain aspects of our Society. I truly believe that challenges are opportunities, so I will bring that perspective into this position and work hard to lead us down a positive pathway."

"I found a communitty that valued my work and provided an amazing forum for scientifite discussion." -itim Rupert

\section{Who Will the TMS Board Welcome Next Year? You Tell Us!}

TMS is now accepting nominations for two positions on the 2022-2025 TMS Board of Directors. The open positions are the Presidential Rotation and the Membership \& Student Development Director. Nominations will be accepted until January 15, 2021. Additionally, positions for Light Metals Division Chair, Materials Processing \& Manufacturing Division Chair, and Structural Materials Division Chair are also open on the 20222025 Board of Directors, but nominations are being developed directly through the technical divisions.

The Presidential Rotation encompasses three successive one-year positions: Vice President, President, and Past President. All three roles are officer positions within the Society and carry unique responsibilities. The role of President includes serving as chair of the Board of Directors.

The Membership \& Student Development Director represents the entire membership in carrying out the professional activities of the Society concerned with professional and student membership and related activities, including diversity and inclusion initiatives.

Applicants' packages for these positions will be considered by the Society's Nominating Committee, which will then recommend a candidate for each position to the Board of Directors.

If approved by the Board of Directors, these endorsed candidates will be presented to the general membership for approval by July 2021 .

To access complete job descriptions and qualifications for each office, as well as the Nominee Statement Form and nomination instructions, visit www.tms.org/BoardNominations.

For additional information, contact Deborah Hixon, TMS Awards Program Administrator, at hixon@tms.org.

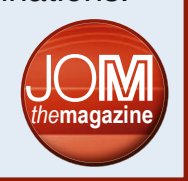

